\title{
Survival after the diagnosis of breast or colorectal cancer in the GAZA Strip from 2005 to 2014
}

\author{
Chiara Panato ${ }^{1 \dagger}$, Khaled Abusamaann $^{2 \dagger}$, Ettore Bidoli ${ }^{1}$, Mokhtar Hamdi-Cherif ${ }^{3}$, Daniela Pierannunzio ${ }^{4}$, \\ Stefano Ferretti ${ }^{5}$, Mahmoud Daher ${ }^{6}$, Fouad Elissawi ${ }^{7}$ and Diego Serraino ${ }^{1,8^{*}}$ (i)
}

\begin{abstract}
Background: Within a dramatic socio-political context, cancer represents a growing health burden in the Gaza Strip. We investigated the survival experience of people diagnosed with breast (BC) or colorectal (CRC) cancer from 2005 to 2014.

Methods: Data included 1360 BC cases (median age 55.1 years) and 722 CRC cases (median age: 59.5 years; 52.5\% men) recorded by the Gaza Cancer Registry according to a standard protocol. Clinical information was available for cases diagnosed in 2005-2006 only. Survival probabilities were estimated by Kaplan-Meyer method, while hazard ratios (HRs) and 95\% confidence intervals (Cl), adjusted for age and sex, were computed to assess factors associated with the risk of death.

Results: Five-year survival was $65.1 \%$ for women with BC and 50.2\% for patients with CRC. Advanced age (> 65 years), stage, and grade increased the death risk. Full access to therapies was associated with a reduced risk of death as compared with patients who had limited access ( $\mathrm{HR}=0.26,95 \% \mathrm{Cl}: 0.13-0.51$ for $\mathrm{BC}$; and $\mathrm{HR}=0.11,95 \% \mathrm{Cl}$ : 0.04-0.31 for (RC).

Conclusion(s): The 5-year survival after BC or CRC in the Gaza Strip was in line with estimates from surrounding Arab countries, but it was much lower than in developed Mediterranean countries (e.g., in Italy or in Jewish people in Israel).
\end{abstract}

Keywords: Gaza Strip, Cancer survival, Breast cancer, Colorectal cancer

\section{Background}

The Gaza Strip, a narrow land located in the southern part of the Occupied Palestinian Territory (OPT), is an overcrowded area with a population of 1.8 million people (i.e., 5000 persons per $\mathrm{km}^{2}$ ) [1]. Although most of the population in the Gaza Strip has a challengeable life, with a high rate of poverty - $74 \%$ of families were estimated to live below the poverty line $[2,3]$ - life expectancy at birth reaches 71.5 years in males and 74.4 years in females [4]. Cancer is the second most common cause

\footnotetext{
* Correspondence: serrainod@cro.it

${ }^{\dagger}$ Chiara Panato and Khaled Abusamaan contributed equally to this work.

${ }^{1}$ Cancer Epidemiology Unit, IRCCS Centro di Riferimento Oncologico, Aviano, Italy

${ }^{8}$ Friuli Venezia Giulia Cancer Registry, IRCCS Centro di Riferimento

Oncologico, Aviano, Italy

Full list of author information is available at the end of the article
}

of death, after cardiovascular diseases, and it accounts for $20 \%$ of the whole expenditure for drugs $[5,6]$.

In the OPT, two population-based cancer registries were established in 1996 by the Palestinian Ministry of Health $(\mathrm{MoH})$-one in the West Bank, and one in the Gaza Strip [4]. Given the geopolitical context of the Gaza Strip [7, 8], the data collection process cannot fully reflect the whole cancer burden in the area. As a consequence, the World Health Organization (WHO) has recently given support to the Palestinian $\mathrm{MoH}$ in improving cancer registration [8]. Of all cases recorded between 2005 and 2014, breast cancer (BC) was the most common cancer among women $(26.0 \%$-skin cancers included), while colorectal cancer (CRC) was the second most common cancer in men ( $9.7 \%$ of all cases).

The Italian $\mathrm{MoH}$ promoted the "EUROMED Cancer Network" with the general aim to support extra-European

(C) The Author(s). 2018 Open Access This article is distributed under the terms of the Creative Commons Attribution 4.0 International License (http://creativecommons.org/licenses/by/4.0/), which permits unrestricted use, distribution, and 
Union Mediterranean countries in the development of effective anti-cancer programs $[9,10]$. The ongoing collaboration with the Gaza Cancer Registry (GCR) was conducted by the National Cancer Institute "Centro di Riferimento Oncologico", Aviano (notheastern Italy); the Italian network of cancer registries (AIRTUM); and the Italian National Health Institute (ISS), Rome.

Herein, we describe the general characteristics and the crude survival experience of patients diagnosed with BC or with CRC between 2005 and 2014 in the Gaza Strip. Furthermore, as selected clinical data were available only for cases diagnosed in 2005-2006, we estimated the risks of death for patients with $\mathrm{BC}$ or $\mathrm{CRC}$ according to type of therapy, disease, grade, or stage.

\section{Methods}

\section{Study population}

We described the general characteristics and the cancer survival experience of people living in the Gaza Strip, diagnosed with BC or CRC in 2005-2014, according to the information recorded in the population-based GCR. Cancer Registries are identified as collectors of personal data for surveillance purposes without the need of explicit individual consent. The approval of a research ethic committee is not required because neither direct nor indirect intervention on patients took place. Nonetheless, the General Director of the Primary Health Care, MoH, (Dr. Fouad Elissawi) cleared the use of the registry data for study purposes. The data collection process used by GCR is an active one, carried on by GCR trained personnel who regularly visit the pathology departments and oncology clinics to collect newly detected cases and to update the already recorded ones. The update of the vital status is manually checked by means of the death registry.

For the aims of this analysis, to ensure data validity, each case was reviewed by a member of the GCR and co-author of this article (FE). The vital status and eventually - the date of death were ascertained from the death registration database at Palestinian $\mathrm{MoH}$. The last follow-up time was December 31st, 2016. Overall, from 2005 to 2014, 1495 women were diagnosed with BC (no cases of $\mathrm{BC}$ were recorded in men during the study period), and 878 people were diagnosed with CRC. This analysis was restricted to $1360 \mathrm{BC}$ and $722 \mathrm{CRC}$ patients after exclusion of: cases lacking the full date of birth (7 $\mathrm{BCs}$ and $21 \mathrm{CRCs})$; children under 15 years of age (2 $\mathrm{BCs}$ and $3 \mathrm{CRCs}$ ); and those patients with coincident dates of diagnosis and death (126 cases of BC and 132 cases of CRC).

Information on therapy, grade, and stage of disease was available for cases diagnosed in 2005-2006 only (i.e., 178 cases of $\mathrm{BC}$ and 80 cases of CRC). Accordingly, for these cases a multivariate analysis was conducted to estimate the risk of death.

\section{Statistical methods}

The crude survival time was calculated as the time elapsed from date of cancer diagnosis to date of death, or to end of follow-up -whichever came first. At univariate analysis, the survival time for the totality of $\mathrm{BC}$ or CRC patients diagnosed from 2005 to 2014 was estimated by means of the Kaplan-Meier method [11].

For cases diagnosed in 2005-2006 only, a multivariate analysis was carried out to statistically assess the role of selected clinical variables on survival. To this end, hazard ratios (HRs) for all-cause mortality, and the corresponding 95\% confidence intervals (95\% CIs), were estimated using the Cox proportional hazard model adjusted for age at diagnosis $(<35,35-44,45-54,55-64$, $65-74,75+$ years) and gender, as appropriate [12]. The proportional hazard assumption was assessed through Schoenfeld residuals, including interactions with follow-up time [12].

\section{Results}

\section{Breast cancer}

The median age of the 1360 women diagnosed with BC in the Gaza Strip between 2005 and 2014 was 55.1 years (Inter Quartile Range -IQR: 45.8-64.8 years). The absolute number of cases more than doubled, from 178 in 2005-2006 up to 396 in 2013-2014 (Table 1), with slight variations in median ages -from 53.0 years (in 20052006 ) to 55.4 years (in 2013-2014). Overall, 76.1\% (95\%

Table 1 Description of breast and colorectal cancer incident cases diagnosed from 2005 to 2014 in the Gaza Strip

\begin{tabular}{|c|c|c|c|c|}
\hline & \multicolumn{2}{|c|}{ Breast cancer } & \multicolumn{2}{|c|}{ Colorectal cancer } \\
\hline & $\begin{array}{l}\text { Cases } \\
N=1360\end{array}$ & $\begin{array}{l}\text { Deaths } \\
N=486(\%)\end{array}$ & $\begin{array}{l}\text { Cases } \\
N=722\end{array}$ & $\begin{array}{l}\text { Deaths } \\
N=361 \text { (\%) }\end{array}$ \\
\hline \multicolumn{5}{|l|}{ Sex } \\
\hline Female & 1360 & $486(35.7)$ & 343 & $169(49.3)$ \\
\hline Male & - & - & 379 & $192(50.7)$ \\
\hline \multicolumn{5}{|c|}{ Age at cancer diagnosis (years) } \\
\hline$\leq 44$ & 331 & $108(32.6)$ & 97 & $33(32.0)$ \\
\hline $45-54$ & 371 & $120(32.4)$ & 163 & $69(40.5)$ \\
\hline $55-64$ & 319 & $112(35.1)$ & 221 & $114(49.3)$ \\
\hline$\geq 65$ & 339 & $146(43.1)$ & 241 & $145(59.3)$ \\
\hline \multicolumn{5}{|c|}{ Calendar year at cancer diagnosis } \\
\hline $2005-2006$ & 178 & $93(52.3)$ & 80 & $58(72.5)$ \\
\hline $2007-2008$ & 207 & $73(35.3)$ & 124 & $53(47.7)$ \\
\hline 2009-2010 & 223 & $101(45.3)$ & 136 & $72(52.9)$ \\
\hline $2011-2012$ & 356 & $143(40.2)$ & 165 & $91(55.2)$ \\
\hline 2013-2014 & 396 & $76(19.2)$ & 217 & $87(40.1)$ \\
\hline
\end{tabular}


CI: 73.7-78.3) of these women was alive after 3 years, 65.1\% (95\% CI: 62.1-67.4) after 5 years, and 51.9\% (95\% CI: 47.9-55.7) after 10 years from BC diagnosis (Fig. 1a). The probability of survival after BC was strongly influenced by age, with women aged 65 years or older showing the lowest survival rates (i.e., $66.0 \%$ after $3,57.4 \%$ after 5 , and $45.1 \%$ after 10 years from diagnosis) $(p<$ 0.001) (Fig. 1b).

Selected clinical data available for the 178 women with BC diagnosed in 2005-2006 are discussed in detail (Table 2). The majority of them (60.1\%) was diagnosed with an advanced stage of disease, but no difference was noted between the percentage of women diagnosed with well or moderately differentiated $\mathrm{BC}$ and those diagnosed with a poorly differentiated or undifferentiated disease. Among these 178 patients with BC, 83.7\% underwent two or more therapies, in particular surgery (87.6\%) and chemotherapy (76,4\%).

The 178 women diagnosed with $\mathrm{BC}$ between 2005 and 2006 were followed-up to December 31st, 2016 for a median period of 63.3 months (IQR: 23.0-100.3 months). During such period, 93 of them (52.2\%) died, and 85 were censored. The estimated median survival time was 83.7 months (95\% CI: 61.3-106.9) (Fig. 2a). Grade and stage of disease influenced the prognosis. Indeed, the survival probabilities of women with advanced stage of disease were statistically lower than those with a localized BC stage ( $p$ of log-rank test $=0.0314)($ Fig. $2 b)$. Concerning HR, advanced stage of disease was associated with an elevated risk of death as compared with those with a localized disease - of borderline statistical significance $-(\mathrm{HR}=1.93,95 \% \mathrm{CI}: 0.98-3.80)$. Likewise, the survival probabilities stratified by grade of disease were different from each other $(p$-value $=0.0078)($ Fig. $2 \mathrm{c})$, and women diagnosed with poorly or undifferentiated $\mathrm{BC}$ were at 1.67 -fold higher risk of death than women with well/moderate grade of cancer (HR:1.67, 95\% CI:1.04-2.69) (Table 2).

Surgically treated women (87.6\%) had the best prognosis, and those treated with two or more anti-cancer therapies presented a statistically significant $70 \%$ reduction in the risk of death, as compared with those who had little (i.e., only one type of treatment) or no access (2.9\%) to anti-cancer therapies (Table 2).

\section{Colorectal cancer}

The median age of the 722 individuals ( $47.5 \%$ women) diagnosed with CRC in the Gaza Strip between 2005 and 2014 was 59.5 years (IQR: $51.2-68.6$ years), and the absolute number of cases ranged from 80 in 2005-2006 to 217 in 2013-2014 (Table 1). The median ages at CRC diagnoses remained stable over time (58.7 years in

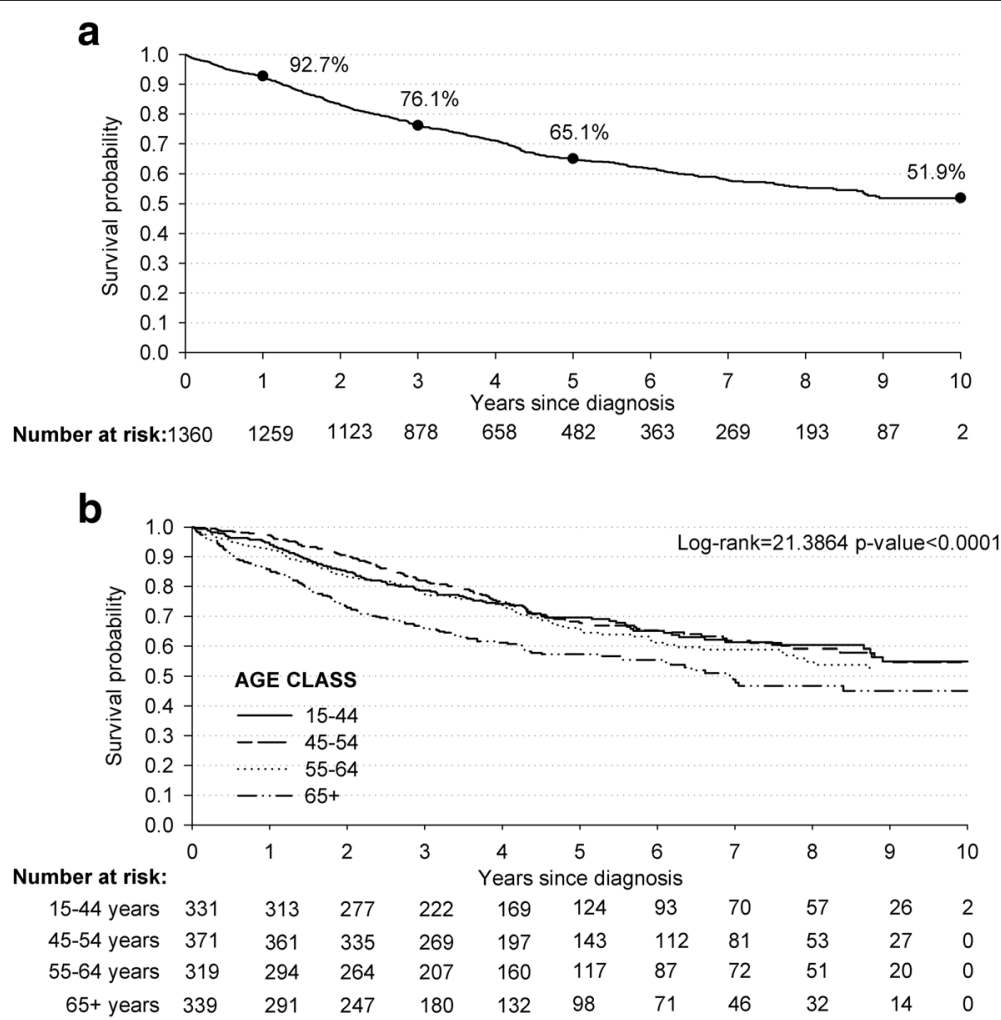

Fig. 1 Kaplan-Meier estimates of survival probabilities among cases 1360 women diagnosed with breast cancer: overall (a) and according to age class (b). Gaza Strip, 2005-2014 
Table 2 Hazard ratios (HR) of all-cause deaths, with corresponding 95\% confidence intervals (Cl), among 178 incident breast cancer cases diagnosed in 2005-2006 in the Gaza Strip according to clinical characteristics

\begin{tabular}{|c|c|c|c|}
\hline & \multirow{2}{*}{$\begin{array}{l}\text { Cases } \\
\mathrm{N}\end{array}$} & \multicolumn{2}{|c|}{ Deaths $(N=93)$} \\
\hline & & $\overline{N(\%)}$ & HR $(95 \% \mathrm{Cl})^{\mathrm{a}}$ \\
\hline \multicolumn{4}{|l|}{ Age at diagnosis (years) } \\
\hline$<55$ & 98 & $47(48.0)$ & $1^{\mathrm{b}}$ \\
\hline$\geq 55$ & 80 & $46(57.5)$ & $1.39(0.93-2.09)$ \\
\hline \multicolumn{4}{|l|}{ Stage ${ }^{c}$} \\
\hline Localized & 33 & $10(30.3)$ & $1^{\mathrm{b}}$ \\
\hline Regional/Distant & 107 & $57(53.3)$ & $1.93(0.98-3.80)$ \\
\hline Missing & 38 & $26(68.4)$ & $2.32(1.10-4.91)$ \\
\hline \multicolumn{4}{|l|}{ Grade } \\
\hline Well and Moderately differentiated & 75 & $31(41.3)$ & $1^{\mathrm{b}}$ \\
\hline Poorly differentiated and Undifferentiated & 70 & $42(60.0)$ & $1.67(1.04-2.69)$ \\
\hline Missing & 33 & $20(60.6)$ & $1.33(0.72-2.44)$ \\
\hline \multicolumn{4}{|l|}{ Surgery ${ }^{c}$} \\
\hline No & 18 & $14(77.8)$ & $1^{\mathrm{b}}$ \\
\hline Yes & 156 & $76(48.7)$ & $0.29(0.16-0.53)$ \\
\hline \multicolumn{4}{|l|}{ Chemotherapy ${ }^{c}$} \\
\hline No & 38 & $23(60.5)$ & $1^{\mathrm{b}}$ \\
\hline Yes & 136 & $67(49.3)$ & $0.58(0.36-0.94)$ \\
\hline \multicolumn{4}{|l|}{ Radiotherapy $^{\mathrm{c}}$} \\
\hline No & 81 & $46(56.8)$ & $1^{\mathrm{b}}$ \\
\hline Yes & 93 & $44(47.3)$ & $0.89(0.57-1.39)$ \\
\hline \multicolumn{4}{|l|}{ Hormone therapy ${ }^{c}$} \\
\hline No & 109 & $63(57.8)$ & $1^{\mathrm{b}}$ \\
\hline Yes & 65 & $27(41.5)$ & $0.53(0.33-0.84)$ \\
\hline \multicolumn{4}{|l|}{ Number of therapies ${ }^{c}$} \\
\hline $0-1$ & 25 & $20(80.0)$ & $1^{\mathrm{b}}$ \\
\hline 2 & 55 & $29(52.7)$ & $0.32(0.18-0.58)$ \\
\hline 3 & 56 & $23(41.1)$ & $0.25(0.13-0.48)$ \\
\hline 4 & 38 & $18(47.4)$ & $0.26(0.13-0.51)$ \\
\hline
\end{tabular}

2005-2006, 59.9 years in 2013-2014). Overall, 59.8\% (95\% CI: $56.0-63.3)$ of them were alive after 3 years, $50.2 \%$ (95\% CI: $46.3-54.0)$ after 5 years, and 40.7\% (95\% CI: 35.6-45.8) after 10 years from diagnosis (Fig. 3a). The survival probabilities after a CRC diagnosis were not influenced by sex (Fig. 3b). Conversely, survival after CRC diagnosis was strongly influenced by age, with patients aged 65 years or older showing the lowest survival rates (i.e., $49.0 \%$ after $3,40.1 \%$ after 5 , and $33.8 \%$ after 10 years from diagnosis) $(p<0.001)$ (Fig. 3c).

Women accounted for $60.0 \%$ of the 80 patients diagnosed in 2005-2006 with a CRC (Table 3). Advanced stage of disease was documented in 49 out of 80 patients (61.3\%), and a well or moderately differentiated grade of cancer was documented in 53 out of 80 patients (66.3\%).
As per clinical protocols, $88.8 \%$ of these 80 cases diagnosed in 2005-2006 underwent surgery, 87.5\% received chemotherapy, and only $27.5 \%$ radiotherapy. More than three quarters of patients underwent two or more therapeutic regimens (Table 3 ).

Figure $4 \mathrm{a}$ shows the overall survival of patients with CRC diagnoses, the median survival time was 43.3 months (95\% CI: 31.4-60.0), and 34 patients were censored. Cases with a localized disease had a higher survival rate (i.e., $61.0 \%$ 5-years survival) than those with regional/distant disease (i.e., 27.1\% 5-years survival) ( $p$-value $=0.0041) \quad$ (Fig. 4b). Furthermore, CRC patients with a regional/distant stage of disease had an elevated risk of death, as compared to those with a localized disease ( $\mathrm{HR}=3.38,95 \% \mathrm{CI}$ : 1.57-7.29) (Table 3). Similarly, 


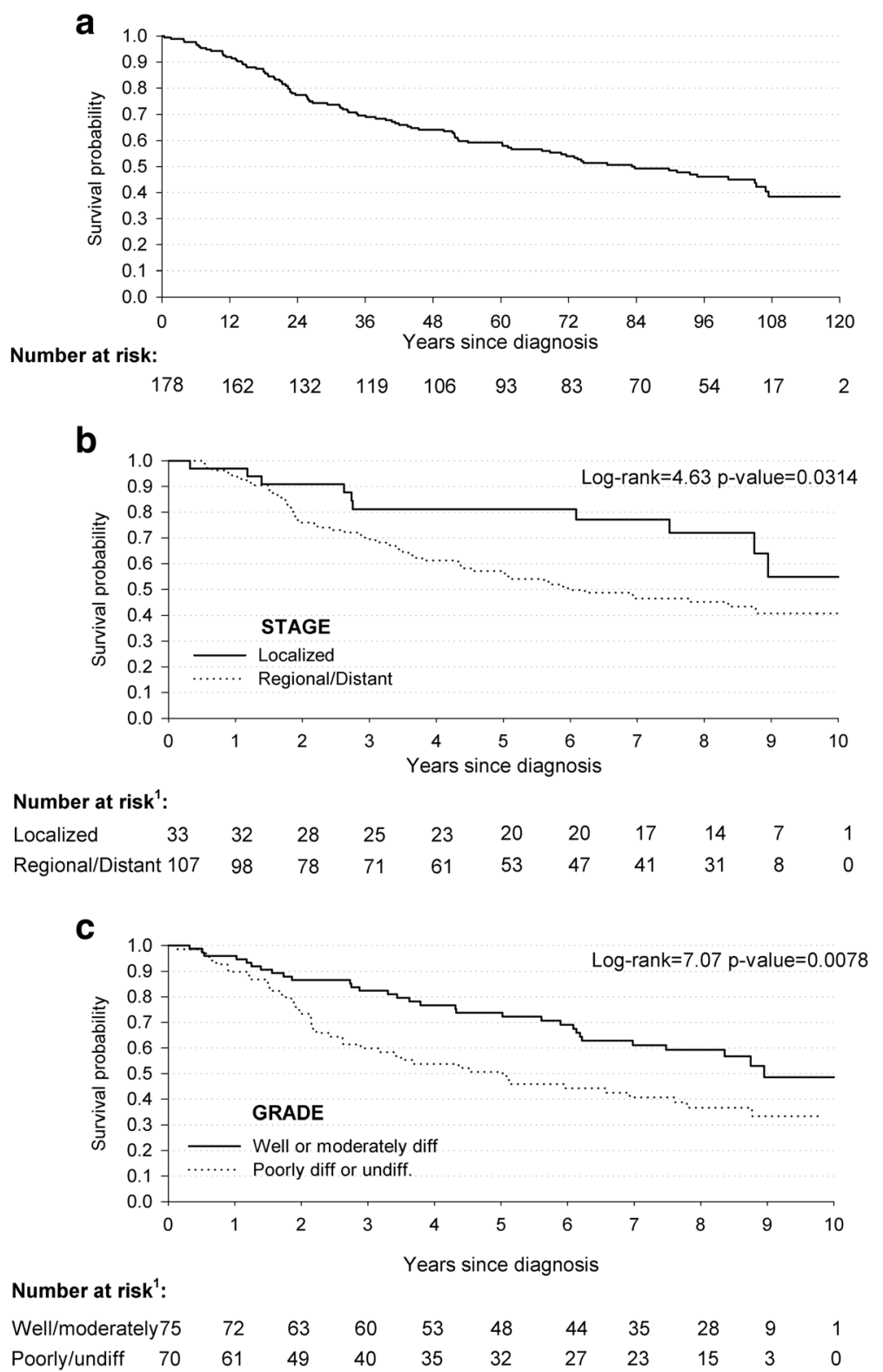

Fig. 2 Kaplan-Meier estimates of survival probabilities among 178 women diagnosed with breast cancer: overall (a); according to stage (b); and grade (c). The Gaza Strip, 2005-2006. 'The sum does not add up to the total because of missing values

survival rates between patients with a well/moderate grade of CRC (i.e., 53.9\% 5-years survival) and those with a poorly or undifferentiated grade (i.e., $13.6 \%$ 5 -years survival) were significantly different (p-value< 0.0001) (Fig. 4c). Likewise, CRC cases diagnosed with poorly or undifferentiated CRC were at 3.57-fold (95\% CI:1.87-6.81) higher risk of death than cases with well/ moderate grade of disease (Table 3).

Patients who had been treated with two or more anti-cancer therapies presented a reduction in the risk of death $(\mathrm{HR}=0.36$ for those who received 2 out of three modalities; $\mathrm{HR}=0.11$ for cases who underwent all 3 types of treatments), as compared with those who had little (i.e., only one type of treatment) or no access (one patient) to anti-cancer therapies (Table 3).

\section{Discussion}

Female $\mathrm{BC}$ and $\mathrm{CRC}$ are among the most common cancers diagnosed every year worldwide in both more- and less-developed WHO regions [13]. These cancers are very common also in the Gaza Strip, where the present study attempted -for the first time- to estimate the survival of people diagnosed with cancer in the Gaza Strip. Our findings indicate that $65.1 \%$ of women with $\mathrm{BC}$, and 

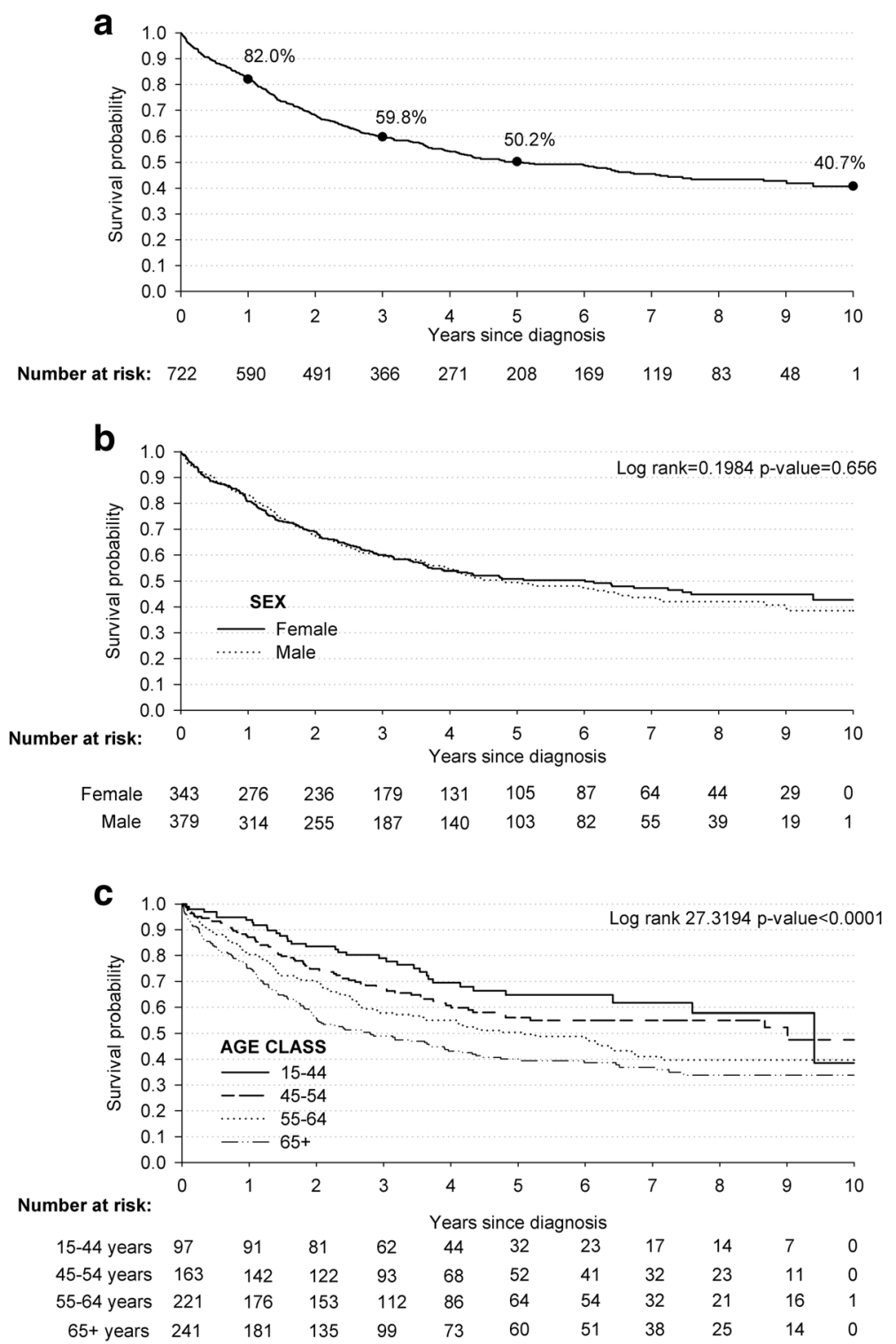

Fig. 3 Kaplan-Meier estimates of survival probabilities among cases 722 cases diagnosed with colorectal cancer: overall (a), according to sex (b) and age class (c). Gaza Strip, 2005-2014

$50.2 \%$ of patients with CRC were alive after 5 years from diagnosis. In the subgroup of patients with available clinical information, the majority of patients were diagnosed at an advanced stage.

In agreement with our results, a Jordanian study disclosed a five-year survival for BC patients of 59.3\%, showing that grade and stage had a significant effect on survival rates [14]. Mean age at breast cancer diagnosis was similar in Jordan [14], in Egypt [15], and in the Gaza Strip. The median survival time after BC in Egypt (i.e., 83.8 months) was equal to the estimate in the Gaza Strip (i.e., 83.7 months) [15] in 2005-2006. Furthermore, in Uganda 5-year survival probability was between 50 and $60 \%$ after a BC diagnosis, and in particular women with the luminal B sub-type had a 5-year survival around $30 \%$. A possible explanation of these results could be the small sample size [16].

Concerning survival after CRC, a study conducted in Israel among Bedouin Arab and Jewish patients with CRC is worth mentioning [17]. The five-year overall survival was about $65 \%$ in both ethnic groups. However, the mean age at diagnosis was lower for the Bedouin Arab population (i.e., 57 years) than for the Jewish population (i.e., 69 years), pointing to a survival disadvantage for the Bedouin Arab ethnic group [17]. The 40\% five-year survival for patients living in the Gaza Strip indicated a greater disadvantage in comparison with both Israeli ethnic groups. 
Table 3 Hazard ratios (HR) of all-cause deaths, with corresponding 95\% confidence intervals (Cl), among 80 cases of colorectal cancers diagnosed in 2005-2006 in the Gaza Strip according to clinical characteristics

\begin{tabular}{|c|c|c|c|}
\hline & \multirow{2}{*}{$\begin{array}{l}\text { Cases } \\
\mathrm{N}\end{array}$} & \multicolumn{2}{|c|}{ Deaths $(N=46)$} \\
\hline & & $\bar{N}(\%)$ & $\operatorname{HR}(95 \% \mathrm{Cl})^{\mathrm{a}}$ \\
\hline \multicolumn{4}{|l|}{ Age at diagnosis (years) } \\
\hline$<60$ & 44 & $23(52.3)$ & $1^{b}$ \\
\hline$\geq 60$ & 36 & $23(63.9)$ & $1.38(0.77-2.48)$ \\
\hline \multicolumn{4}{|l|}{ Sex } \\
\hline Male & 32 & $20(62.5)$ & 1 \\
\hline Female & 48 & $26(54.2)$ & $0.88(0.48-1.59)$ \\
\hline \multicolumn{4}{|l|}{ Stage ${ }^{c}$} \\
\hline Localized & 27 & $10(37.0)$ & $1^{b}$ \\
\hline Regional/Distant & 49 & $35(71.4)$ & $3.38(1.57-7.29)$ \\
\hline \multicolumn{4}{|l|}{ Grade $^{c}$} \\
\hline Well and moderately differentiated & 53 & $23(43.4)$ & $1^{b}$ \\
\hline Poorly differentiated and Undifferentiated & 22 & $19(86.4)$ & $3.57(1.87-6.81)$ \\
\hline \multicolumn{4}{|l|}{ Surgery } \\
\hline No & 9 & $9(100.0)$ & $1^{\mathrm{b}}$ \\
\hline Yes & 71 & $37(52.1)$ & $0.27(0.13-0.62)$ \\
\hline \multicolumn{4}{|l|}{ Chemotherapy } \\
\hline No & 10 & $8(80.0)$ & $1^{b}$ \\
\hline Yes & 70 & $38(54.3)$ & $0.37(0.16-0.87)$ \\
\hline \multicolumn{4}{|l|}{ Radiotherapy } \\
\hline No & 58 & $38(65.5)$ & $1^{b}$ \\
\hline Yes & 22 & $8(36.4)$ & $0.24(0.10-0.56)$ \\
\hline \multicolumn{4}{|l|}{ Number Therapies } \\
\hline $0-1$ & 18 & $16(88.9)$ & $1^{b}$ \\
\hline 2 & 40 & $22(55.0)$ & $0.36(0.17-0.74)$ \\
\hline 3 & 22 & $8(36.4)$ & $0.11(0.04-0.31)$ \\
\hline
\end{tabular}

${ }^{\mathrm{a}}$ Estimated using Cox proportional hazard model adjust for sex and age; ${ }^{\mathrm{b}}$ Reference category; ${ }^{\mathrm{c}}$ The sum does not add up to the total because of missing values

The comparison of data from the GCR with those from highly-developed countries highlighted substantial differences. In the Gaza Strip, the percentage of BC patients with localized disease at diagnosis was about half than that recorded in most European countries, and similar to the picture described in eastern European countries [18]. For CRC cases, the proportion of localized diseases in the Gaza Strip was about two-fold higher than that documented by Italian cancer registries [19]. With respect to treatment, the proportion of patients in the Gaza Strip who underwent chemotherapy and/or radiotherapy was higher than the proportion of Italian patients ( $88 \%$ vs. 39 and $28 \%$ vs. $10 \%$, respectively).

In contrast with widely available estimates of cancer incidence rates, survival estimates at population level in less developed countries -including the WHO EMR- are less common [20]. The 5-year raw survival after BC varied substantially, from $38.8 \%$ in Setif (Algeria) [20] to
71.1\% in Izmir, Turkey, in women diagnosed from 1995 to 1997 and followed-up to 2003, or to $61.3 \%$ in Saudi Arabia, among women diagnosed in 1994-1996 and followed-up to 2001 [21]. Similar variations emerged, at population level for survival after CRC diagnosis, from a raw 5 -year survival of nearly $23 \%$ in Setif to $52 \%$ in Izmir [20].

Among the study strengths, the survival of cancer patients living in the Gaza Strip was assessed at a population level, while other studies were previously conducted in clinical setting [22, 23]; moreover, we described the heterogeneity survival. On the other hand, accuracy and completeness of data collection, in this study, might have suffered of potential limitations. With regards to the accuracy of information, the data from the GCR may have suffered of limitations due to the socio-economic situation and to the conflicts in the Gaza Strip, which may have limited the activity of the health personnel working in the West Bank and in Gaza. Furthermore, 

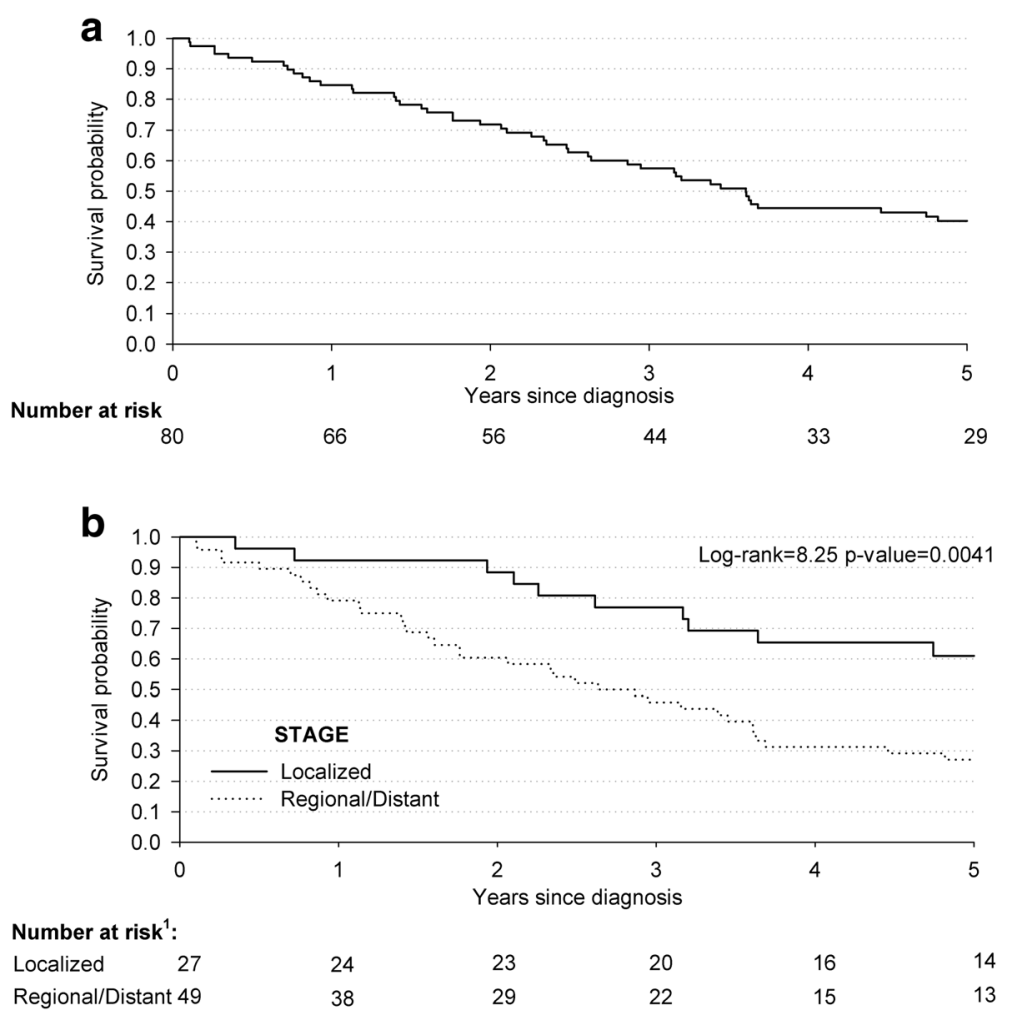

\begin{tabular}{|c|c|c|c|c|}
\hline Localized & 24 & 23 & 20 & 16 \\
\hline gional/Distant 49 & 38 & 29 & 22 & 15 \\
\hline
\end{tabular}
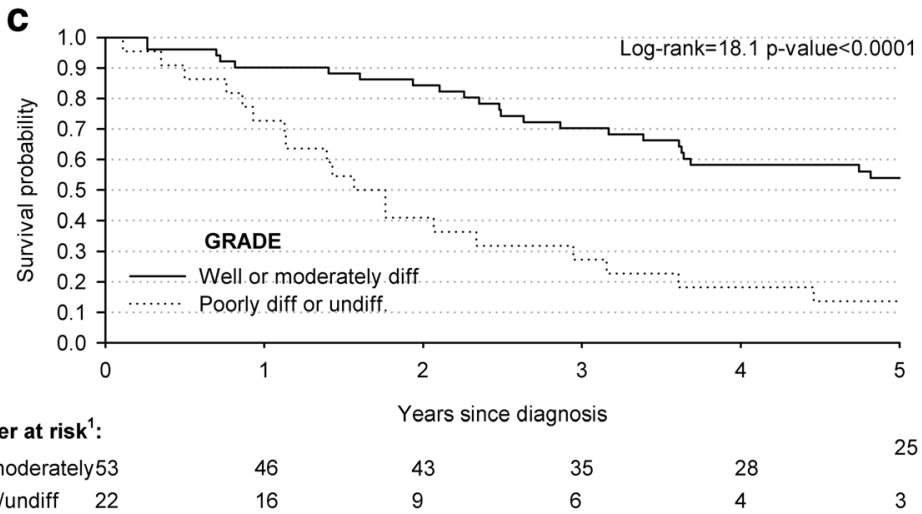

Fig. 4 Kaplan-Meier estimates of survival probabilities among 80 cases diagnosed with colorectal cancer: overall (a); according to stage (b); and grade (c). The Gaza Strip, 2005-2006. 'The sum does not add up to the total because of missing values

because of cultural taboos (e.g., negative and false perception toward cancer patients with a consequent isolation from family members), cancer patients tend to conceal their disease, which hinders their access to local hospitals. Concerning completeness, although cancer registration in the Gaza Strip started in 1996, it still faces several obstacles such as lack of appropriate hardware and software, insufficient staff, and training of health personnel. All these concerns represent key issues in the accurate assessment of the cancer burden in the Gaza Strip.

Notwithstanding this lack of completeness, our study results represent one of the first attempts to provide updated indications on the state of oncologic health care in the Gaza Strip. Moreover, it tries to address the problematic cancer care situation in this population.

The closure policy of the Gaza Strip for security reasons has caused an isolation of Gaza citizens. This isolation has affected the possibility to have adequate cancer care for many cancer patients living in the Gaza Strip. In particular, the denial or delay of permits to travel outside Gaza Strip for cancer patients referred to its two neighbouring countries (namely, Israel and Egypt) limits the opportunity of adequate diagnosis and/or treatment. Moreover, a number of antineoplastic medications are denied to patients due to the embargo [5, 24]. 


\section{Conclusions}

In view of this already acknowledged difficult social, political, and economical context, the results from the present oncologic investigation further stresses the need to thoroughly re-assess and overcome the obstacles to a proper delivery of health care to the people living in the Gaza Strip. It is the scope of the continuing collaboration between Italian cancer registries and the GCR to contribute in supplying updated oncologic data from the Gaza Strip.

\section{Abbreviations}

BC: Breast cancer; Cls: Confidence intervals; CRC: Colorectal cancer; EMR: Eastern Mediterranean region; GCR: Gaza Cancer Registry; HRs: Hazard ratios; IQR: Inter Quartile Range; MoH: Ministry of Health; OPT: Occupied Palestinian Territory; WHO: World Health Organization

\section{Acknowledgements}

The authors wish to thank Mrs. Luigina Mei for editorial assistance.

\section{Funding}

This work was supported by the Italian Ministry of Health - project title: "Sorveglianza epidemiologica per il controllo delle malattie neoplastiche nei paesi del Mediterraneo: dalla registrazione del cancro ai modelli statistici" (Grant N.: 185J12000380005).

Role of funding body: The funding body had no direct role in study design and data collection, in the data analysis and interpretation, as well as in the manuscript writing.

\section{Availability of data and materials}

The datasets used and/or analysed during the current study are available from the Gaza Cancer Registry (point of contact: MS Haia,

haiayaghi@yahoo.com) upon reasonable request.

\section{Authors' contributions}

DS conceived and designed the study; CP, DS and KA drafted the article; MD and FE collected and assembled the data; CP and EB performed the statistical analyses; MHC, SF and DP provided support in the interpretation of results; all Authors critically reviewed and approve the manuscript for submission.

\section{Ethics approval and consent to participate}

Cancer Registries are identified as collectors of personal data for surveillance purposes without the need of explicit individual consent. The approval of a research ethic committee is not required as this descriptive study was conducted without any direct or indirect intervention on patients. Nonetheless, The General Director (Dr. Fouad Elissawi) of the Primary Health Care, MoH, Gaza Strip, has cleared the use of registry data for study purposes (letter dated April 8, 2015).

\section{Competing interests}

The authors declare that they have no competing interests.

\section{Publisher's Note}

Springer Nature remains neutral with regard to jurisdictional claims in published maps and institutional affiliations.

\footnotetext{
Author details

${ }^{1}$ Cancer Epidemiology Unit, IRCCS Centro di Riferimento Oncologico, Aviano, Italy. ${ }^{2}$ Ministry of Health, PHC, Training and Education Department, Gaza, Palestine. ${ }^{3}$ Faculty of Medicine and Cancer Registry, University of Setif, Setif, Algeria. ${ }^{4}$ Centro Nazionale di Epidemiologia, Sorveglianza e Promozione della Salute, Istituto Superiore di Sanità, Rome, Italy. ${ }^{5}$ Dipartment Morfologia, Chirurgia e Medicina Sperimentale, Università di Ferrara - Registro Tumori Area Vasta Emilia Centrale, Azienda USL Ferrara, - Servizio Prevenzione collettiva e Sanità pubblica, Ferrara, Regione Emilia-Romagna, Italy. ${ }^{6} \mathrm{WHO}$ Office. Occupied Palestinian Territory, UNDP Building, Elnasr Street, Gaza, Palestine. ${ }^{7}$ Ministry of Health, Primary Health Care directorate, Gaza, Palestine.
}

${ }^{8}$ Friuli Venezia Giulia Cancer Registry, IRCCS Centro di Riferimento Oncologico, Aviano, Italy.

Received: 3 October 2017 Accepted: 24 May 2018

Published online: 04 June 2018

\section{References}

1. Palestinian Central Bureau of Statistics. Palestine in Figures 2015. Ramallah Palestine. 2016. http://www.pcbs.gov.ps/Downloads/book2188.pdf (Last access: 29 Aug 2017).

2. Giacaman R, Khatib R, Shabaneh L, Ramlawi A, Sabri B, Sabatinelli G, et al. Health status and health services in the occupied Palestinian territory. Lancet. 2009;373:837-49.

3. UNRWA. United Nations Relief and works agency: Gaza in 2020 a liveable place? A report by the United Nations country team in the occupied Palestinian territory, August 2012. United Nations: Jerusalem. 2012. https:// www.unrwa.org/newsroom/press-releases/gaza-2020-liveable-place (last access: 29 Aug 2017).

4. Ministry of Health. Health Status in Palestine-Ministry of Health Annual report 2014. Palestine. 2015. http://www.moh.gov.ps/portal/Arabic version. (last access: 29 Aug 2017).

5. Husseini A, Abu-Rmeileh NM, Mikki N, Ramahi TM, Ghosh HA, Barghuthi N et al. Cardiovascular diseases, diabetes mellitus, and cancer in the occupied Palestinian territory. Lancet. 2009;373:1041-9.

6. Ministry of Health. Palestinian Health Information Center (PHIC), Pharmaceutica situation in Gaza-2015. Palestine. 2016. http://www.moh.gov.ps/portal/wpcontent/uploads/2015 pharmacy (arabic). (Last access: 29 Aug 2017).

7. American Cancer Society. Global Cancer Facts \& Figures 2nd Edition. Atlanta, USA: American Cancer Society; 2011e. Available at: http:// oralcancerfoundation.org/wp-content/uploads/2016/03/acspc-027766.pdf.

8. WHO. World Health Organization. occupied Palestinian territory (oPT). Situation report \# 2, 27 December 2015; http://www.emro.who.int/pse/ palestine-infocus/situation-reports.html (Last access: 29 Aug 2017).

9. Giordano L, Bisanti L, Salamina G, Ancelle Park R, Sancho-Garnier H, Espinas J, et al. The EUROMED CANCER network: state-of-art of cancer screening programmes in non-EU Mediterranean countries. Eur J Pub Health. 2016;26:839.

10. Hamdi Cherif M, Serraino D, Mahnane A, Laouamri S, Zaidi Z, Boukharouba $\mathrm{H}$, et al. Time trends of cancer incidence in Setif, Algeria, 1986-2010: an observational study. BMC Cancer. 2014;14(637) https://doi.org/10.1186/14712407-14-637.

11. Armitage P, Berry G, Matthews JNS. Statistical methods in medical research. 4th ed. Malden: Blackwell Science; 2002.

12. Kalbfleish J, Prentice R. The statistical analyses of failure time data. 2nd ed. New York: Wiley; 2002.

13. Ferlay J, Soerjomataram I, Ervik M, Dikshit R, Eser S, Mathers C, et al. GLOBOCAN 2012 v1.0, Cancer incidence and mortality worldwide: IARC CancerBase no. 11. Lyon, France: International Agency for Research on. Cancer. 2013; Available at: http://globocan.iarc.fr

14. Arkoob K, Al-Nsour M, Al-Nemry O, Al-Hajawi B. Epidemiology of breast cancer in women in Jordan: patient characteristics and survival analysis. East Mediterr Health J. 2010;16:1032-8.

15. Seedhom AE, Kamal NN. Factors affecting survival of women diagnosed with breast Cancer in El-Minia governorate. Egypt Int J Prev Med. 2011; 2:131-8.

16. Galukande $M$, Wabinga $H$, Mirembe F. Breast cancer survival experiences at a tertiary hospital in sub-Saharan Africa: a cohort study. World J Surg Oncol. 2015;13:220. https://doi.org/10.1186/s12957-015-0632-4.

17. Smirnov M, Lazarev I, Perry ZH, Ariad S, Kirshtein B. Colorectal cancer in southern Israel: comparison between Bedouin Arab and Jewish patients. Int J Surg. 2016;33(Part A):109-16.

18. Allemani C, Sant M, Weir K, Richardson LC, Baili P, Storm H, et al. Breast cancer survival in the US and Europe: a CONCORD high-resolution study. Int J Cancer. 2013;132:1170-81.

19. Minicozzi P, Kaleci S, Maffei S, Allemani C, Giacomin A, Caldarella A, et al. Disease presentation, treatment and survival for colorectal cancer patients: a EUROCARE high-resolution study. Eur J Pub Health. 2013;24:98-100.

20. Coleman MP, Quaresma M, Berrino F, Lutz JM, De Angelis R, Capocaccia R, et al. Cancer survival in five continents: a worldwide population-based study (CONCORD). Lancet Oncol. 2008;9:730-56. 
21. Sankaranarayanan R, Swaminathan R, Brenner H, Chen K, Chia KS, Chen JG, et al. Cancer survival in Africa, Asia, and central America: a population-based study. Lancet Oncol. 2010;11:165-73.

22. Ibrahim AS, Khaled HM, Mikhail NN, Baraka H, Kamel H. Cancer incidence in Egypt: results of the National Population-Based Cancer Registry Program. J Cancer Epidemiol. 2014;2014:1-18. https://doi.org/10.1155/2014/437971

23. Lakkis NA, Adib SM, Osman MH, Musharafieh UM, Hamadeh GN. Breast cancer in Lebanon: incidence and comparison to regional and western countries. Cancer Epidemiol. 2010;34:221-5.

24. WHO. Access to health services for Palestinian people: case studies of five patients in critical conditions who died while waiting to exit the Gaza Strip. West Bank and Gaza: World Health Organization, 2008. Available at: http:// applications.emro.who.int/dsaf/EMROPUB_2008_EN_753.pdf?ua=1. Last access: 16/03/2018.

Ready to submit your research? Choose BMC and benefit from:

- fast, convenient online submission

- thorough peer review by experienced researchers in your field

- rapid publication on acceptance

- support for research data, including large and complex data types

- gold Open Access which fosters wider collaboration and increased citations

- maximum visibility for your research: over $100 \mathrm{M}$ website views per year

At BMC, research is always in progress.

Learn more biomedcentral.com/submissions 